\title{
Matriz de insumo-Produto de Pernambuco PARA 1999: METODOLOGIA DE CÁLCULO E SUBSÍDIOS AO PLANEJAMENTO REGIONAL*
}

\author{
Ecio de Farias Costa ${ }^{\S}$ \\ Ignácio Tavares de Araújo Júnior \\ Jocildo Fernandes Bezerra ${ }^{\dagger}$ \\ Marcelo Virginio Melo
}

\begin{abstract}
RESUMO
O trabalho apresenta uma metodologia para a construção de uma matriz de insumo-produto para o Estado de Pernambuco para o ano de 1999. Este modelo de equilíbrio geral permite que políticas de geração de emprego, renda e valor adicionado, necessárias para o desenvolvimento do Estado, sejam elaboradas por meio da abordagem do insumo-produto. A partir dos resultados da matriz de insumo-produto, indicadores do grau de interligação setorial da economia pernambucana, efeitos de choques de demanda sobre emprego, renda e valor adicionado são apresentados, bem como os impactos de uma política de adensamento de cadeias produtivas via internalização das importações. Os resultados apresentados servem de orientação para a elaboração racional de políticas públicas para o planejamento regional dos policy-makers.
\end{abstract}

Palavras-chave: matriz de insumo-produto, multiplicadores de impacto, índices de ligação.

\begin{abstract}
This study presents an approach for computing an input-output matrix for the state of Pernambuco for 1999. This general equilibrium model allows for job, income and added value generation policies, necessary for state development, built on an input-output framework. Based on results from the input-output matrix, indicators of sector linkages in Pernambuco's economy, effects of demand shocks on jobs, income and added value, as well as impacts of production chains development policy via imports internalization are presented. Results presented are intended to be used in the rational making of public policies for regional planning by policy-makers.
\end{abstract}

Key words: input-output matrix, impact multipliers, linkage indices.

JEL classification: R15, R13, R58.

\footnotetext{
* Este artigo é resultado do projeto de Matriz de Insumo-Produto de Pernambuco para 1999, desenvolvido pelo Instituto de Pesquisas Sociais Aplicadas (IPSA), com suporte financeiro da Federação das Indústrias do Estado de Pernambuco (FIEPE) e Serviço de Apoio às Micro e Pequenas Empresas do Estado de Pernambuco (SEBRAE-PE). Os autores agradecem a Alexandre Alves Porsse, da Fundação de Economia e Estatística (FEE), pelo apoio técnico, crucial para a consolidação do estudo. Todavia, erros e omissões são de exclusiva responsabilidade dos autores.

$\S \quad$ Professor de Economia, Departamento de Economia/Pós-Graduação em Economia, (PIMES), Universidade Federal de Pernambuco (UFPE). Bolsista CNPq. M.S. e Ph.D. em Economia Agrícola, University of Geórgia. E-mail: ecio@yahoo.com Telefone: (81)2126-8378, Ramal 221/Fax: (81)2126-8381, Ramal 207

a Professor de Economia, Departamento de Economia, Universidade Federal da Paraíba, Doutorando, Pós-Graduação em Economia (PIMES) da UFPE. E-mail: igtav@bol.com.br

$\dagger$ Professor de Economia, Departamento de Economia / Pós-Graduação em Economia, (PIMES), Universidade Federal de Pernambuco (UFPE). Mestre e Doutor em Economia, Universidade de São Paulo. E-mail: j.nl@uol.com.br

$\ddagger$ Analista Socioeconômico do Instituto Brasileiro de Geografia e Estatística (IBGE). Mestre em Economia, Universidade Federal de Pernambuco (UFPE). E-mail: marcelomelo@ibge.gov.br

Recebido em setembro de 2004. Aceito em junho de 2005.
} 


\section{INTRODUÇÃO}

Os estudos sobre o grau de articulação entre atividades produtivas, usando a metodologia das matrizes de insumo-produto, são comuns na maioria dos países, sobretudo naqueles de economias mais industrializadas. O uso altamente difundido dessa técnica nas últimas décadas tem refletido a influência de vários fatores, dentre eles o desenvolvimento de métodos estatísticos de coleta de dados que disponibilizaram informações importantes sobre o funcionamento das economias num formato próprio para usos nas matrizes de insumo-produto. Além disso, vale destacar o fato de a Organização das Nações Unidas (ONU, 1999) ter identificado essa metodologia como um importante instrumento para fins de planejamento econômico nas economias em desenvolvimento, já que por meio dele é possível conhecer, de forma detalhada, os impactos de variações na demanda final, resultantes de ações de políticas governamentais, sobre a estrutura produtiva. (Miller e Blair, 1985).

Note-se, porém, que sendo o principal propósito do modelo insumo-produto analisar a interdependência das atividades numa economia, ele também se constitui num instrumento valioso para a aplicação prática de conceitos modernos, como os de cadeias produtivas e de complexos industriais.

As cadeias produtivas são difíceis de serem identificadas, tanto nas economias desenvolvidas como naquelas mais atrasadas, embora, em cada caso, por motivos diferentes. Nas economias industrializadas, a dificuldade provém da interligação geral entre as atividades e das amplas possibilidades de substituição entre os insumos, enquanto nas demais economias o problema comum é o desdobramento do tecido produtivo. (Haguenauer et al., 2001).

Neste último caso, o modelo de insumo-produto ainda fornece uma razoável orientação por meio da estimativa de impactos entre setores no interior dos quais se localizam determinados complexos industriais, e dependendo do grau de desagregação permitido pelos dados é possível identificar a importância de muitos dos elos do sistema. ${ }^{1}$

Essa possibilidade se materializa, sobretudo, porque o sistema insumo-produto engloba uma malha de atividades que se interligam exatamente por meio de compras e vendas de insumos a montante e a jusante de cada elo de produção.

O objetivo deste trabalho é apresentar os resultados da estimativa de uma matriz de insumoproduto (matriz de Leontief) para o Estado de Pernambuco, com dados de 1999, alguns deles obtidos diretamente do Instituto Brasileiro de Geografia e Estatística - IBGE, outros calculados por meio de metodologias que são explicadas ao longo do texto. Também são apresentados resultados derivados da matriz de Leontief, como os índices de ligação para frente e para trás (forward e backward linkages) a partir dos quais se torna possível identificar os setores-chave da economia penambucana. Ademais, foram calculados multiplicadores de impacto sobre emprego, renda e valor adicionado, parâmetros importantes na orientação de policy-makers para a elaboração de políticas de incentivo industrial e desenvolvimento econômico regional.

O estudo é composto de seis partes, incluindo esta introdução, distribuídas da seguinte maneira: na segunda parte apresenta-se a estrutura geral da matriz de insumo-produto; na terceira, faz-se uma descrição sobre a origem dos dados, seu tratamento e diversas formas de utilização; na quarta parte, discorre-se sobre a metodologia de cálculo da matriz de insumo-produto; na quinta, os indicadores síntese e multiplicadores são apresentados, seguidos de uma análise de adensamento de cadeias produtivas via internalização de importações, e na sexta parte são oferecidas algumas conclusões.

1 No caso das estatísticas industriais do IBGE, o nível de desagregação vai até quatro dígitos. 


\section{ESTRUTURA GERAL DA MATRIZ DE INSUMO-PRODUTO}

A matriz de insumo-produto de Pernambuco (MIP-PE) contempla 36 grupos de atividades econômicas (inclusive dummy financeiro) e 63 grupos de produtos, classificados em conformidade com a pauta de atividades e produtos da MIP do Brasil. (IBGE, 1997a). A escolha das atividades e produtos que compõem o modelo foi realizada observando a participação de cada um deles no contexto econômico pernambucano daquela época. Os setores relacionados são aqueles de maior representatividade da economia de Pernambuco. ${ }^{2}$

Uma vez definidos os grupos de atividades e produtos, partiu-se para a construção das Tabelas de Recursos e Usos - TRU (IBGE, 1997b), a base para a elaboração do modelo de insumo-produto. Na Tabela de Recursos encontram-se todos os elementos que compõem a oferta total de bens e serviços da economia, a saber: produção local e importações internacionais e interestaduais, representadas na seguinte equação:

$$
\mathrm{OT}=\mathrm{d}+\mathrm{t}+\mathrm{VP}+\mathrm{m}_{\mathrm{I}}+\mathrm{m}_{\mathrm{E}}
$$

em que OT é a oferta total, d e t representam vetores contendo as margens de distribuição (comércio e transporte) e de impostos sobre os produtos e importações, VP é o valor da produção a preços básicos, $\mathrm{m}_{\mathrm{I}}$ e $\mathrm{m}_{\mathrm{E}}$ correspondem às importações internacionais e interestaduais.

$\mathrm{Na}$ Tabela de Usos são apresentados todos os elementos que compõem a demanda total, a saber: consumo intermediário e demanda final (exportações - internacionais e interestaduais, gastos do governo, consumo das famílias, estoque de capital e formação bruta do capital fixo), representados nas seguintes equações:

$$
\begin{aligned}
& \text { DT }=C I+d f \\
& d f=x_{I}+x_{E}+g+c f+k+v
\end{aligned}
$$

em que DT é a demanda total por bens e serviços, CI é o consumo intermediário a preço de mercado, df é a demanda final, $x_{\mathrm{I}}$ e $\mathrm{x}_{\mathrm{E}}$ são as exportações internacionais e interestaduais, $\mathrm{g}$ corresponde ao consumo do governo, cf é o consumo das famílias, k é o estoque de capital e vé a variação de estoques.

Os valores de oferta e demanda total devem ser tais que a igualdade observada na equação 2.4 seja obedecida em todos os produtos e na economia como um todo,

$$
\mathrm{OT}=\mathrm{DT}
$$

A construção das TRU é um processo intensivo em dados e não existe uma fonte única disponível que atenda às necessidades de informações estatísticas das TRU. Portanto, manipularam-se várias bases de dados até chegar aos valores de oferta e demanda total de cada produto. Porém, via de regra, a identidade 2.4 não foi satisfeita em nenhum deles, ou seja, existiam desequilíbrios (diferenças entre demanda e oferta) em todos os produtos.

2 Ver Tabelas A1 e A2 no Anexo para melhor compreensão da agregação de atividades e produtos utilizadas a partir da MIP do Brasil para a MIP de Pernambuco. 
Para sanar este problema lançou-se mão de um exercício de balanceamento, que consiste no confronto entre as informações estatísticas referentes à oferta e demanda no mercado de cada produto, com o objetivo de alcançar o equilíbrio em todos os setores considerados e na economia como um todo. A condução do balanceamento exigiu um instrumento onde pudessem ser observados todos os elementos de oferta e de demanda de cada produto. Para tal, utilizaram-se planilhas de equilíbrio, cujo formato, único para todos os produtos, pode ser observado em um exemplo de uma planilha já equilibrada na Tabela $1 .^{3}$

Como pode ser observado na Tabela 1, todas as informações sobre oferta e demanda do produto madeira e mobiliário estão reportadas. Os valores primários que alimentam essas planilhas provêm das TRU. Dessa forma, no lado da oferta, são preenchidas as células da primeira coluna (preço básico) e da linha nomeada total dos recursos (oferta total a preço básico, margem de distribuição e impostos) cuja soma horizontal resulta na oferta total a preço de mercado do produto. Já no lado da demanda, são preenchidas as células da última coluna, cujas informações sobre os usos são valoradas a preço de mercado e cuja soma vertical resulta na demanda total a preço de mercado do produto. Portanto, o balanceamento é realizado nessas bordas, com vistas a promover o equilíbrio (igualdade) entre as informações estatísticas sobre oferta e demanda a preço de mercado.

Tabela 1 - Planilha de equilíbrio entre oferta e demanda - MIP-PE, 1999 - Produto: 1001 - Madeira e Mobiliário ( $\mathrm{R} \$$ mil)

\begin{tabular}{|c|c|c|c|c|c|c|c|c|c|c|}
\hline \multirow[b]{2}{*}{ Operação } & \multirow{2}{*}{$\begin{array}{l}\text { Preço } \\
\text { Básico }\end{array}$} & \multirow[t]{2}{*}{ MC } & \multirow[t]{2}{*}{ MT } & \multirow{2}{*}{$\begin{array}{l}\text { Margem de } \\
\text { Distribuição } \\
\text { (MC + MT) }\end{array}$} & \multicolumn{5}{|c|}{ Impostos } & \multirow{2}{*}{$\begin{array}{l}\text { Preço } \\
\text { de } \\
\text { Mercado }\end{array}$} \\
\hline & & & & & Import. & $\mathrm{IPI} / / \mathrm{SS}$ & ICMS & Outros & Total & \\
\hline \multicolumn{11}{|l|}{ Oferta (ou recursos) } \\
\hline Produção & 89.784 & 11.650 & 3.486 & 15.136 & 0 & 793 & 11.442 & 1 & 12.237 & 117.156 \\
\hline Importação de outros estados & 207.805 & 26.963 & 8.069 & 35.032 & 0 & 1.837 & 26.483 & 3 & 28.322 & 271.159 \\
\hline Importação do resto do mundo & 2.581 & 335 & 100 & 435 & 427 & 23 & 329 & 0 & 779 & 3.795 \\
\hline Total dos Recursos & 300.170 & 38.947 & 11.656 & 50.603 & 427 & 2.653 & 38.254 & 4 & 41.337 & 392.110 \\
\hline \multicolumn{11}{|l|}{ Demanda (ou usos) } \\
\hline Consumo intermediário & 110.841 & 12.660 & 3.789 & 16.449 & 169 & 0 & 0 & 1 & 171 & 127.461 \\
\hline Consumo pessoal & 130.915 & 18.187 & 5.443 & 23.630 & 243 & 1.835 & 26.476 & 2 & 28.557 & 183.102 \\
\hline Formação bruta de capital fixo & 7.335 & 1.019 & 305 & 1.324 & 14 & 103 & 1.483 & 0 & 1.600 & 10.259 \\
\hline Variação de estoques & 225 & 31 & 9 & 41 & 0 & 3 & 46 & 0 & 49 & 315 \\
\hline Exportações p/ outros estados & 50.770 & 7.040 & 2.107 & 9.147 & 0 & 710 & 10.249 & 1 & 10.960 & 70.877 \\
\hline Exportações $p /$ resto do mundo & 83 & 10 & 3 & 12 & 0 & 1 & 0 & 0 & 1 & 96 \\
\hline Total dos Usos & 300.170 & 38.947 & 11.656 & 50.603 & 427 & 2.653 & 38.254 & 4 & 41.337 & 392.110 \\
\hline Saldo & 0 & 0 & 0 & 0 & 0 & 0 & 0 & 0 & 0 & 0 \\
\hline
\end{tabular}

Fonte: Elaboração própria.

3 A planilha na Tabela 1 é uma adaptação do modelo usado pelo IBGE para a geração da MIP do Brasil. (Nunes, 1998). 
O processo de balanceamento exigiu o conhecimento de algumas especificidades da economia pernambucana, assim como a forma de interação entre as atividades consideradas, por meio do encadeamento produtivo. Desta forma, as tabelas nunca eram balanceadas de forma individual. A título de ilustração, a planilha de equilíbrio do produto açúcar, pertencente ao setor industrial, foi balanceada simultaneamente com a planilha do produto cana-de-açúcar, um produto do setor agropecuário. Portanto, o processo de balanceamento não se resume à aplicação de métodos matemáticos (ver Guilhoto et al., 2002), mas também incorpora na sua operacionalização uma lógica econômica consistente com a realidade do Estado de Pernambuco em 1999 e as dependências intersetoriais observadas.

Em alguns produtos não foi possível, via técnicas de balanceamento, “zerar” o saldo entre oferta e demanda. Tal excedente, em geral de baixo valor, foi alocado na célula do consumo intermediário (planilha de equilíbrio) do produto e distribuído entre os setores da atividade por meio do método biproporcional RAS, ${ }^{4}$ aplicado na matriz de consumo intermediário setorial. A aplicação do método RAS consiste na multiplicação da matriz de coeficientes técnicos por vetores contendo coeficientes de ajuste. Este processo foi repetido até a matriz convergir para uma matriz compatível com a situação de equilíbrio entre oferta e demanda desejada.

Terminado o balanceamento das planilhas de equilíbrio, e tendo atingido a igualdade entre os valores da oferta e da demanda, para cada produto, as demais células são preenchidas por meio de distribuição proporcional da margem de distribuição e impostos conforme estrutura obtida das colunas a preço básico (lado da oferta) e a preço de mercado (lado da demanda).

A MIP-PE contempla apenas o consumo intermediário que se origina da produção do Estado. Portanto, foi necessário desmembrar o consumo intermediário total em três componentes: consumo intermediário com origem na produção local; consumo intermediário de origem na produção de outros estados; e consumo intermediário com origem na produção de outros países. Estes resultados são gerados nas tabelas de destino fazendo uso das informações encontradas nas tabelas de equilíbrio. Para realizar esta desagregação supôs-se, inicialmente, que: i) todas as exportações são provenientes da produção estadual; e ii) o valor da oferta em cada origem distribui-se conforme a proporcionalidade dos componentes da demanda a preços básicos.

Os resultados obtidos foram objeto de análise, utilizando-se, como parâmetros de avaliação, informações adicionais das bases estatísticas. Estas informações consistem basicamente na identificação dos valores passíveis de associação com os componentes da demanda (consumo intermediário, consumo das famílias e formação de capital), obtidos a partir de um levantamento da nomenclatura da pauta de importações (interestadual e internacional). Em alguns casos, as hipóteses acima assumidas foram relaxadas, pois verificou-se que alguns dos produtos eram exportados por Pernambuco, porém eram produzidos em estados vizinhos. Nas tabelas de destino também foram calculados os valores do consumo intermediário e da produção estadual a preços básicos.

O procedimento acima descrito permitiu o cálculo da matriz de consumo intermediário valorada a preço básico, cuja origem é a produção estadual. A seguir, será detalhada a metodologia de estimação dos elementos de oferta e de demanda utilizados para encontrar a referida matriz.

4 Para mais detalhes sobre o método RAS, ver Bacharach (1970) e Miller e Blair (1985). 


\section{TRATAMENTO DAS INFORMAÇÕES ESTATÍ́STICAS ${ }^{5}$}

O tratamento das informações primárias que entram nas TRU antes de iniciar o balanceamento depende diretamente de sua disponibilidade. ${ }^{6} \mathrm{Na}$ maioria das variáveis levantadas aqui, o IBGE, por meio de suas pesquisas diretas, é a fonte de dados. Para os casos em que não foi possível utilizar dados do IBGE, utilizaram-se formas secundárias. Os procedimentos descritos nas seções subseqüentes referem-se à geração primária dos valores, sendo que o resultado final é função do processo de balanceamento.

\subsection{Valor da produção}

Os valores dos produtos pertencentes às indústrias classificadas como extrativa e de transformação (classificação 02 a 27) foram obtidos da Pesquisa Industrial Anual - PIA de 1999. (IBGE, 2001). A abertura das informações se dá em nível de até quatro dígitos da Classificação Nacional das Atividades Econômicas (CNAE) para empresas com 30 ou mais pessoas ocupadas.

O valor da produção do setor agropecuária (01) foi obtido, inicialmente, do Censo Agropecuário de 1996 (IBGE, 1998) e atualizado para 1999 com a variação nominal da produção agropecuária das Contas Regionais do Estado de Pernambuco. (IBGE, 2002). Dado que o Censo não possui boa cobertura das pequenas propriedades, as informações dos produtos da lavoura apresentaram forte viés para baixo. Neste sentido, optou-se por manter as informações das Contas Regionais somente para os produtos que compõem a lavoura, porém substituindo a variação de preços da Produção Agropecuária Municipal - PAM (IBGE, 2003), calculada, implicitamente, pela variação de preços da pesquisa da Fundação Getúlio Vargas - FGV (2003) em alguns produtos: trigo, batata e mandioca. Este ajuste foi necessário para corrigir as distorções na variação dos preços verificada na PAM e adequar o valor de produção desses produtos à realidade da lavoura em Pernambuco.

$\mathrm{Na}$ maior parte dos demais setores, os dados utilizados são provenientes das Contas Regionais, exceto para o setor comunicações (32), cujo valor de produção é aquele sem ajuste para fechamento das Contas Regionais com os demais estados do Brasil..$^{8}$ No entanto, em alguns segmentos do setor de serviços a fonte das informações é a Pesquisa Anual de Serviços - PAS (IBGE, 2001) de 1999: para as atividades transporte (31) e serviços prestados às famílias e empresas (34) e para os produtos alojamento e alimentação (3401) e outros serviços (3402). Destaca-se também que o setor comércio (30) incorpora o segmento reparação e serviços auxiliares.

Por fim, em todas as atividades nas quais as informações não provêm das Contas Regionais foi somada, ao valor bruto da produção, uma parcela referente ao produto dos trabalhadores autônomos desses setores. A magnitude dessa parcela foi gerada pela aplicação da relação entre valor de produção e valor adicionado das pequenas empresas (Censo de 1985) no rendimento dos autônomos da Pesquisa Anual por Amostra de Domicílios - PNAD, de 1999 (IBGE, 2000), em cada setor. A finalidade deste procedimento foi incorporar no cálculo do valor da produção da economia per-

5 No Anexo encontra-se um quadro-resumo referente a cada informação e suas respectivas fontes (ver Tabela A3).

6 A metodologia de tratamento dos dados segue, em grande parte, a de Porsse (2002).

7 As informações da PIA representam melhor a realidade da estrutura industrial de PE, comparativamente aos dados das Contas Regionais do IBGE, haja vista que a PIA incorpora empresas com cinco ou mais pessoas ocupadas. Além disso, a PIA produz informações atualizadas para o ano de 1999, enquanto que a metodologia das Contas Regionais é baseada na aplicação de índices de volume e preços numa estrutura estabelecida no Censo Industrial de 1985. Esta metodologia pode ficar comprometida quando as informações de volume e preços não são plenamente capturadas pelas pesquisas estatísticas, notadamente em períodos de forte aceleração inflacionária, tal como ocorreu na economia brasileira nos anos 1980 e 1990.

8 A aplicação de coeficientes de ajuste nas informações estatísticas estaduais faz parte da metodologia do IBGE quando do cálculo do PIB do Brasil. 
nambucana a produção do setor informal. Uma conduta semelhante foi adotada por Porsse (2002) para contabilizar o valor da produção nas TRUs do Rio Grande do Sul.

\subsection{Importações e exportações}

Os dados de importações e exportações internacionais foram obtidos da Secretaria de Comércio Exterior - SECEX (Ministério do Desenvolvimento, Indústria e Comércio, 2003), consistindo num total de 2.486 registros de produtos, classificados conforme a Nomenclatura Comum do Mercosul (NCM). Os valores estão em dólar FOB para as exportações e em dólar CIF para as importações e foram convertidos para reais pela taxa de câmbio média anual em 1999, obtida do Banco Central do Brasil (2003). Em seguida, procedeu-se à compatibilização da NCM com a CNAE e, por conseguinte, à agregação dessas informações na pauta de 63 produtos.

Os dados de importações e exportações interestaduais foram fornecidos pela Secretaria da Fazenda de PE, consistindo num total de 749 registros de produtos, classificados conforme o Código de Atividades Econômicas (CAE), o qual é baseado na NCM. A base de informações do CAE foi compatibilizada com a NCM, e depois com a CNAE, a fim de promover a agregação na pauta de 63 produtos.

\subsection{Margem de distribuição e impostos}

Devido à dificuldade de obter estatísticas sobre margens de comércio e transporte dos setores da atividade econômica tomou-se como ponto de partida a relação dessas com o valor da oferta total a preço básico da Tabela de Recursos do Brasil em 1999, para obter o vetor (preliminar) de margem de distribuição dos produtos da Tabela de Recursos de Pernambuco.

Esses valores foram criticados e ajustados durante as fases de balanceamento. A crítica e o ajuste foram realizados combinando-se análise econômica, discussão com pesquisadores e informações dos órgãos representativos dos setores. Com respeito aos impostos de importações internacionais, IPI/ISS e outros e ICMS, os valores totais para o Estado foram obtidos da Regionalização das Transações do Setor Público - RTSP. (IBGE, 2002). Como as alíquotas dos impostos de importações internacionais e do IPI são respectivamente iguais para cada produto, independente do Estado da Federação, colocou-se, por hipótese, que a mesma proporção desses em relação à sua oferta de produto na Tabela de Recursos do Brasil em 1999 aplica-se a PE. O mesmo raciocínio foi usado para distribuir o ISS e outros impostos, tendo em vista que seus valores são pouco expressivos.

Por outro lado, a quantificação do ICMS por produto foi realizada com informações da Secretaria de Fazenda de PE, que forneceu uma base de dados com 749 registros de arrecadação sobre produtos, classificados conforme o CAE. Inicialmente, fez-se uma correspondência do CAE com a CNAE e, depois, agregaram-se esses 749 registros conforme a pauta de 63 produtos.

\subsection{Consumo intermediário}

O consumo intermediário total de cada setor foi valorado a preços de mercado, e as fontes estatísticas do valor deste consumo em cada setor foram, respectivamente, as mesmas utilizadas no levantamento do valor de produção dos setores (seção 3.1). Analogamente, para os setores em que as informações não provêm das Contas Regionais foi somada, ao consumo intermediário, uma parcela referente aos autônomos desses setores, calculada por meio da relação entre valor do consumo 
intermediário e valor adicionado das pequenas empresas aplicada no rendimento dos autônomos, em cada setor.

Uma vez determinado o valor do consumo intermediário total em cada setor, foi necessário distribuir esse valor nos 63 grupos de produtos definidos, a fim de identificar a estrutura técnica de insumo necessária à realização da produção em cada setor. Como não existe fonte estatística exaustiva para tanto, o primeiro passo foi aplicar a estrutura nacional calculada com base na Tabela de Usos do Brasil em 1999. Exemplificando, calculou-se: ${ }^{9}$

$$
Z_{i j}^{P E}=\left(\frac{Z_{i j}^{B R}}{Z_{j}^{B R}}\right) Z_{j}^{P E}=a_{i j}^{B R} Z_{i j}^{P E}
$$

em que $Z_{\mathrm{ij}}^{\mathrm{PE}}$ é o consumo do produto i pelo setor j em Pernambuco, $Z_{\mathrm{j}}^{\mathrm{PE}}$ é o consumo total do setor

$\mathrm{j}$ em $\mathrm{PE}, \mathrm{Z}_{\mathrm{ij}}^{\mathrm{BR}}$ é consumo do produto i pelo setor $\mathrm{j}$ no Brasil e $\mathrm{Z}_{\mathrm{j}}^{\mathrm{BR}}$ é o consumo total do setor $\mathrm{j}$ no Brasil. Os coeficientes nacionais menores que 0,05 foram zerados para, num primeiro momento, concentrar a análise nos principais produtos.

Tomando o total da i-ésima linha da matriz de consumo intermediário, tem-se o total do iésimo produto destinado aos setores econômicos. Esses valores, para cada produto, foram transportados para a respectiva célula da planilha de equilíbrio entre oferta e demanda e ajustados na fase de balanceamento, para absorver os excedentes (saldos) e, assim, levar ao equilíbrio de mercado.

O ajustamento implica revisar a distribuição dos valores nas linhas e colunas e realocá-los de forma a se adequarem à estrutura produtiva da economia de Pernambuco. Logo, além da transposição de valores entre os setores, algumas células zeradas são preenchidas durante o processo de ajuste. No final, o resultado obtido é uma matriz de consumo intermediário distinta daquela do Brasil e compatível com a configuração produtiva de Pernambuco.

Novamente, é importante frisar que esses ajustes sempre combinam a modelagem matemática com a análise do encadeamento dos setores produtivos no que tange à relação insumo-produto. Neste momento, informações secundárias (qualitativas) obtidas das associações setoriais, sindicatos e outras entidades de classes, assim como consultas com técnicos especializados nos setores do Estado são agregadores de consistência no trabalho. Porém, dada à dificuldade de se gerar um ajuste perfeito nos saldos, uma pequena parcela dos excedentes é distribuída pela utilização do método RAS. Aqui se usou uma versão modificada do RAS, pois os valores cuja confiança é maior são fixados e, portanto, não sofrem alteração durante a execução do mecanismo de interação responsável pela distribuição dos excedentes (saldos).

\subsection{Consumo do governo e das famílias}

O valor do consumo final das administrações públicas corresponde ao valor total da produção de serviços não-mercantis públicos, deduzidos os pagamentos parciais realizados pelas famílias, que constam no consumo familiar. Portanto, este valor é obtido diretamente das Contas Regionais.

O consumo das famílias constitui um importante componente da demanda final. Ele foi estimado utilizando as informações de consumo familiar presentes na Pesquisa de Orçamentos Fami-

9 Este método não foi usado apenas no setor administração pública (35), cujo valor total do consumo intermediário foi distribuído conforme estrutura de participação porcentual obtida do Balanço Geral do Estado de PE em 1999. 
liar - POF de 1996 (IBGE, 1999), realizada na Região Metropolitana de Recife (RMR). Da POF, foram utilizadas as propensões médias para encontrar o consumo das famílias da RMR por faixa de renda. O consumo das famílias que não moram na RMR foi calculado multiplicando-se o valor de consumo encontrado RMR pelo índice:

$$
\mathrm{h}=\frac{\text { FRMR }}{\text { FRNMR }}
$$

em que FRMR é o número de famílias que moram na RMR e FRNMR é o número de famílias da região que não moram na RMR por faixa de renda. Esta última informação foi obtida na PNAD de 1996, uma pesquisa que foi conduzida no mesmo ano em que foi realizada a POF.

As estimativas obtidas mostraram que $66,5 \%$ do consumo familiar de Pernambuco era realizado na região metropolitana, enquanto isto $33,5 \%$ era feito na região não metropolitana, um resultado coerente com realidade econômica pernambucana, onde $68 \%$ do PIB estadual se concentra na região metropolitana e $32 \%$ no restante do Estado.

Em seguida, o vetor de consumo das famílias foi compatibilizado para a pauta de 80 produtos das TRU brasileiras de 1996. Por conseguinte, fez-se a compatibilização deste vetor de consumo das famílias para a pauta dos 63 produtos da MIP de Pernambuco. Aplicando-se um índice de valor do consumo das famílias de 1996 a 1999, expandiu-se o consumo encontrado, resultando no consumo das famílias de 1999.

\subsection{Formação bruta de capital fixo e variação de estoques}

Os procedimentos de cálculo que originaram os números da formação bruta de capital fixo (FBCF) e da variação de estoques (VE) foram realizados por etapas, ou seja, pelas partes que compõem a formação. Conceitualmente, a formação bruta de capital (FBC) é definida como:

$$
\begin{aligned}
& \mathrm{FBC}=\mathrm{FBCF}+\mathrm{VE} \\
& \mathrm{FBCF}=\mathrm{CC}+\mathrm{ME}+\mathrm{O}
\end{aligned}
$$

em que CC indica construção civil, $\mathrm{ME}$ significa máquinas e equipamentos e $\mathrm{O}$ indica outros.

No cálculo da FBCF do Brasil o IBGE leva em conta o valor das construções, dos equipamentos instalados, dos meios de transporte, dos serviços de montagem e instalações de máquinas, do produto reflorestamento e formação de cultura permanentes, despesas com a pesquisa para prospecção de petróleo etc. Tais informações não estão contabilizadas para a economia pernambucana. Assim, não foi possível calcular diretamente a FBCF do Estado. Desta forma, tanto a FBCF como a VE de Pernambuco foram estimadas utilizando as metodologias descritas a seguir.

A estimativa da FBCF baseou-se, inicialmente, nas relações brasileiras em nível dos produtos, chegando-se ao total da FBCF pela soma. Então, estabeleceu-se um coeficiente “c”, que reflete quanto da oferta de cada produto é FBCF, no Brasil. Ou seja, tomando-se a oferta a preços de mercado de cada produto $\left(\mathrm{O}_{\mathrm{i}}\right)$, menos as exportações $\left(\mathrm{X}_{\mathrm{i}}\right)$, “c” estabelece qual proporção é destinada à FBCF. Esquematizando: ${ }^{10}$

10 As exportações referem-se ao comércio internacional e interestadual. Os valores resultantes deste cálculo, cuja participação no total da FBCF situavam-se abaixo de $0,3 \%$, foram zerados. 
$c_{i}=\frac{\mathrm{FBCF}_{\mathrm{i}}^{\mathrm{BR}}}{\mathrm{O}_{\mathrm{i}}^{\mathrm{BR}}-\mathrm{X}_{\mathrm{i}}^{\mathrm{BR}}}$

$\mathrm{FBCF}_{\mathrm{i}}=\mathrm{c}_{\mathrm{i}}\left(\mathrm{VP}_{\mathrm{i}}^{\mathrm{PE}}-\mathrm{X}_{\mathrm{i}}^{\mathrm{PE}}\right)$

Já o valor total da VE foi estimado pela seguinte relação:

$$
\mathrm{VE}^{\mathrm{PE}}=\left(\frac{\mathrm{VE}^{\mathrm{BR}}}{\mathrm{PIB}^{\mathrm{BR}}}\right) \mathrm{PIB}^{\mathrm{PE}}
$$

Posteriormente, este valor foi distribuído entre os produtos da MIP-PE conforme a estrutura de participação individual proveniente da Tabela de Usos do Brasil, previamente compatibilizada com a pauta de produtos de Pernambuco.

\section{CÁlCULO DA MATRIZ DE INSUMO-PRODUTO}

Concluída a construção das TRU, partiu-se para o cálculo efetivo de matriz de coeficientes técnicos diretos e da matriz de Leontief, utilizando as informações sobre demanda e oferta, a preços básicos, cuja obtenção foi viabilizada por meio da utilização das planilhas de equilíbrio, onde foram identificados os destinos dos impostos e das margens de distribuição.

Nas tabelas de destino, o consumo intermediário das atividades foi desagregado em três componentes conforme a sua origem: i) proveniente da produção local, ii) proveniente de outros estados, iii) proveniente de outros países. Esta decomposição é necessária porque apenas a matriz de consumo intermediário de origem doméstica é utilizada na construção da matriz de coeficientes técnicos.

De posse da matriz de consumo intermediário originária da produção local, $\mathrm{U}(n \times m),{ }^{11}$ do vetor de demanda final, $\operatorname{df}(n \times 1)$, composto pelas exportações, consumo do governo e das famílias e FBCF, e a matriz de produção local, $\mathrm{V}(n \times m)$, pode-se escrever as seguintes identidades:

$$
\begin{aligned}
& q=U \cdot i+d f \\
& q=V \cdot i \\
& g=V^{\prime} \cdot i \\
& \sum_{j=1}^{m} g_{j}=\sum_{i=1}^{n} q_{i}
\end{aligned}
$$

11 Neste modelo, $n$ indica o número de produtos e $m$ o número de atividades econômicas. 


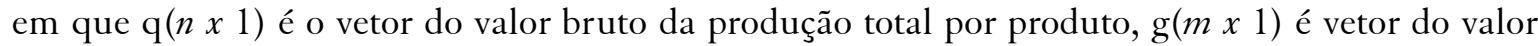
bruto da produção total por atividade e i é um vetor unitário $(n \times 1)$.

Um ponto que merece nota neste trabalho é o fato de que um modelo de insumo-produto requer que cada produto seja fornecido apenas por uma atividade econômica. Esta propriedade é também chamada de hipótese de homogeneidade. Identificar os setores que produziram os bens e serviços consumidos pelos demais setores é um ponto importante do modelo de Leontief. De forma diversa, Feijó et al. (2003) colocam que a matriz de coeficientes técnicos de Leontief procura responder aos seguintes questionamentos:

Como a demanda por produtos é transmitida às atividades?

Conhecida a demanda das atividades, como são determinados seus insumos?

A primeira questão é respondida assumindo a hipótese de market-share, ou que a demanda é alocada proporcionalmente ao seu valor de produção pelas as atividades. Matematicamente, podese formalizar que a hipótese de market-share constante é expressa por meio de uma matriz D de dimensão $(m \times n)$ :

$$
\mathrm{D}=\mathrm{V}^{\prime} \cdot(q)^{-1}, \quad \mathrm{~d}_{\mathrm{ji}}=\frac{\mathrm{V}_{\mathrm{ji}}}{\mathrm{q}_{\mathrm{i}}}
$$

em que os elementos em D, resultantes da multiplicação, denotam a participação porcentual do produto i na produção total do(s) produto(s) da atividade $\mathrm{j}$.

Para responder ao segundo questionamento utiliza-se a hipótese de tecnologia do setor. Em outras palavras, assume-se que a tecnologia de produção dos produtos é uma característica da atividade que os produz. Matematicamente, esta hipótese pode ser representada por um matriz de coeficientes técnicos, $\mathrm{B}$, produto $(n)$ por atividade $(m)$ calculada da seguinte forma:

$$
B=U \cdot(g)^{-1}, \quad b_{i j}=\frac{u_{i j}}{g_{j}}
$$

em que os elementos da matriz $\mathrm{B}(n \times \mathrm{m})$ representam a participação do produto i consumido pelo setor j em relação à produção total do setor j. Agora, substituindo 4.5 em 4.1 tem-se:

$$
q=B \cdot g^{\prime} \cdot i+d f=B \cdot g+d f
$$

Multiplicando ambos os lados da equação 4.4 pelo vetor unitário i, obtém-se:

$$
\mathrm{g}=\mathrm{D} \cdot \mathrm{q}
$$

Por fim, substituindo 4.6 em 4.7 obtém-se o modelo de Leontief associado às matrizes, atividade por atividade:

$$
g=(I-D \cdot B)^{-1} \cdot(D \cdot d f)
$$

em que D·df é a demanda final por atividade, D·B é a matriz de coeficientes técnicos diretos atividade por atividade e $(\mathrm{I}-\mathrm{D} \cdot \mathrm{B})^{-1}$ é a matriz de impacto intersetorial (matriz de Leontief). 


\section{RESUltados}

Utilizando os procedimentos matemáticos acima descritos, chegou-se a um extenso conjunto de tabelas contendo uma série de indicadores macroeconômicos do Estado de Pernambuco para o ano de 1999, os quais foram utilizados para o cálculo do PIB estadual pelas três óticas. Ademais, foram geradas tabelas de destino a partir das quais pode-se identificar a origem e o destino de todos os bens e serviços consumidos em Pernambuco, assim como estão reportados todos os elementos de oferta e demanda avaliados a preços básicos e de mercado.

Em virtude da insuficiência de espaço não é possível expor todos os resultados neste trabalho. Além da matriz de insumo-produto apresentada no Anexo (Tabela A4), são reportados apenas, dois dos resultados derivados da matriz de Leontief. São eles: os indicadores síntese ou índices de ligação para frente e índices de ligação para trás e os multiplicadores de impacto sobre a renda, emprego e valor adicionado de cada atividade considerada.

\subsection{Indicadores síntese}

Os indicadores síntese ou índices de ligações para frente $\left(\mathrm{I}_{\mathrm{F}}\right)$ e para trás $\left(\mathrm{I}_{\mathrm{B}}\right)$ identificam os setores-chave na economia. Os valores calculados para os índices de ligações para trás indicam quanto o setor demanda de outros setores da economia, enquanto os índices de ligações para frente mostram o quanto o setor é demandado pelas outras indústrias. (Guilhoto et al., 2002). De outra forma, diz-se que estes índices medem o encadeamento entre os setores considerados na matriz de Leontief. $\mathrm{O}$ índice de ligação para frente de um setor $i$ também pode ser interpretado como sendo o aumento total da produção de todos os setores da economia quando há um aumento unitário pela demanda final do setor $i$. Quanto ao índice de ligação para trás, este pode ser visto como sendo o aumento da produção do setor $i$ quando acontece um aumento unitário na demanda final da economia.

Os setores-chave da economia podem ser identificados por meio dos indicadores síntese, quando estes são calculados em relação à média. Definindo $\mathrm{Z}$ como a matriz de Leontief, os índices de ligações para frente e para trás são obtidos pelas seguintes expressões:

$$
\begin{aligned}
& I_{F}=Z \cdot i \\
& I_{B}=i \cdot Z
\end{aligned}
$$

em que $\mathrm{Z}$ é a matriz de impacto intersetorial (matriz de Leontief); e i é um vetor unitário.

Os valores calculados desses índices para os setores considerados neste estudo foram examinados buscando-se destacar os índices de comportamento acima da média. Para tanto, os índices são normalizados. A construção de índices normalizados é necessária para possibilitar a identificação de setores-chave, em que índices normalizados com média superior a 1 (um) indicam que o setor tem comportamento acima da média, no caso, setores-chave da economia pernambucana. Os índices normalizados são encontrados calculando-se, inicialmente, a média dos coeficientes, por meio das seguintes fórmulas:

$$
\overline{\mathrm{I}}_{\mathrm{Bj}}=\frac{\sum_{\mathrm{j}=1}^{\mathrm{m}} \mathrm{Z}_{\mathrm{ij}}}{\mathrm{n}}
$$




$$
\overline{\mathrm{I}}_{\mathrm{Fi}}=\frac{\sum_{\mathrm{i}=1}^{\mathrm{n}} \mathrm{Z}_{\mathrm{ij}}}{\mathrm{n}}
$$

Em seguida, calcula-se a média total dos coeficientes pela fórmula,

$$
M T=\frac{\sum_{i=1}^{n} \sum_{j=1}^{m} Z_{i j}}{n^{2}}
$$

Por fim, os índices de ligação para frente e para trás normalizados são calculados da seguinte forma:

$$
\begin{gathered}
\mathrm{I}_{\mathrm{FN}}=\frac{\overline{\mathrm{IF}_{\mathrm{i}}}}{\mathrm{MT}} \\
\mathrm{I}_{\mathrm{BN}}=\frac{\overline{\mathrm{IB}_{\mathrm{j}}}}{\mathrm{MT}}
\end{gathered}
$$

$\mathrm{Na}$ Tabela 2 estão reportados os valores dos índices para frente e para trás normalizados. As atividades onde o índice excede a unidade são consideradas setores-chave da economia pernambucana. Estes estão destacados com um fundo cinza. Destacam-se sete setores-chave da economia pernambucana quanto ao encadeamento para frente. Dentre eles, um é o setor Agropecuária; dois pertencem à indústria; e quatro deles pertencem ao setor serviços, com destaque para o setor Serviços Prestados às Famílias, que apresenta o maior índice de ligação para frente. Este resultado é um claro sinal da importância do setor serviços na economia pernambucana, que além de responder por uma importante parcela do PIB estadual, possui o grande potencial de elevar o nível de produção dos demais setores. Um raciocínio análogo pode ser feito para interpretar o resultado do setor Agropecuária, cabendo lembrar a importância da cultura da cana-de-açúcar na composição do valor adicionado deste setor. Examinando os índices de ligação para trás na produção, verifica-se a existência de 16 setores-chave. Estes números sugerem, por exemplo, que a Indústria do Açúcar é o setor da economia pernambucana cuja produção tem uma maior resposta a um aumento da demanda final da economia, uma vez que ele apresenta o maior valor entre os demais índices de ligação para trás. De forma mais ampla, estes índices também sugerem que os setores que pertencem à indústria de alimentos (Beneficiamento de Produtos de Origem Vegetal, Inclusive Fumo; Abate e Preparação de Carnes; Resfriamento e Preparação do Leite e Laticínios; Óleos Vegetais e Gorduras para Alimentação; e, Outras Indústrias Alimentares e de Bebidas, com Exceção da Industria do Café) estão entre os que sofrem maior impacto de um aumento da demanda final da economia. No que concerne ao setor Agropecuária, a despeito da sua importância para elevar a produção das demais atividades da economia, como indica o índice de ligação para frente, ele não figura entre as atividades que mais respondem a aumentos na demanda final da economia, não sendo um setorchave no encadeamento para trás. Quanto aos demais, percebe-se que das cinco atividades que compõem o setor serviços, exclusive o setor Administração Pública, três são setores-chave no encadeamento para trás. Por fim, é importante destacar que os setores de Indústria Química, Serviços 
Industriais de Utilidade Pública, Comércio, e Comunicações são setores-chave no encadeamento tanto para frente como para trás. Portanto, são os setores que estão entre os mais importantes da economia pernambucana, devendo merecer atenção especial dos tomadores de decisão no momento de planejar os rumos da economia pernambucana.

Tabela 2 - Índices de ligação para frente e para trás normalizados, MIP-PE 1999

\begin{tabular}{|c|c|c|c|c|c|}
\hline Código & Descrição da atividade & $\mathrm{I}_{\mathrm{FN}}$ & Rank & $\mathrm{I}_{\mathrm{BN}}$ & Rank \\
\hline 01 & Agropecuária & 3,10 & 2 & 0,994 & 22 \\
\hline 02 & Indústria Extrativa & 0,54 & 26 & 0,972 & 26 \\
\hline 03 & Minerais Não-metálicos & 0,63 & 20 & 1,039 & 07 \\
\hline 04 & Siderurgia & 0,60 & 22 & 0,984 & 25 \\
\hline 05 & Metalurgia dos Não-ferrosos & 0,61 & 21 & 0,988 & 24 \\
\hline 06 & Fabricação de Outros Produtos Metalúrgicos & 0,77 & 13 & 1,005 & 16 \\
\hline 07 & Fabricação e Manutenção de Máquinas e Tratores & 0,50 & 28 & 0,997 & 20 \\
\hline 08 & Material Elétrico-eletrônico & 0,74 & 15 & 0,997 & 19 \\
\hline 09 & Autoveículos, Peças e Acessórios & 0,49 & 30 & 0,926 & 30 \\
\hline 10 & Madeira e Mobiliário & 0,48 & 32 & 0,998 & 18 \\
\hline 11 & Indústria de Papel e Gráfica & 0,73 & 16 & 1,025 & 11 \\
\hline 12 & Indústria da Borracha & 0,41 & 35 & 0,898 & 33 \\
\hline 13 & Indústria Química & 1,01 & 7 & 1,055 & 06 \\
\hline 14 & Refino de Petróleo e Indústria Petroquímica & 0,89 & 10 & 0,878 & 34 \\
\hline 15 & Fabricação de Produtos Farmacêuticos e de Perfumaria & 0,59 & 24 & 0,961 & 28 \\
\hline 16 & Indústria de Transformação de Material Plástico & 0,78 & 12 & 0,928 & 29 \\
\hline 17 & Indústria Têxtil & 0,86 & 11 & 0,971 & 27 \\
\hline 18 & Fabricação de Artigos do Vestuário e Acessórios & 0,59 & 23 & 0,999 & 17 \\
\hline 19 & Fabricação de Calçados e de Artigos de Couro e Pele & 0,49 & 31 & 0,919 & 31 \\
\hline 20 & Indústria do Café & 0,59 & 25 & 0,805 & 35 \\
\hline 21 & Beneficiamento de Produtos de Origem Vegetal, Inclusive Fumo & 0,65 & 17 & 1,036 & 09 \\
\hline 22 & Abate e Preparação de Carnes & 0,48 & 33 & 1,135 & 03 \\
\hline 23 & Resfriamento e Preparação do Leite e Laticínios & 0,52 & 27 & 1,013 & 15 \\
\hline 24 & Indústria do Açúcar & 0,75 & 14 & 1,155 & 01 \\
\hline 25 & Óleos Vegetais e Gorduras para Alimentação & 0,64 & 19 & 1,025 & 10 \\
\hline 26 & Outras Indústrias Alimentares e de Bebidas & 0,96 & 8 & 1,085 & 04 \\
\hline 27 & Indústrias Diversas & 0,49 & 29 & 0,995 & 21 \\
\hline 28 & Serviços Industriais de Utilidade Pública & 1,63 & 5 & 1,149 & 02 \\
\hline 29 & Construção Civil & 0,64 & 18 & 1,020 & 12 \\
\hline 30 & Comércio & 2,87 & 3 & 1,016 & 13 \\
\hline 31 & Transporte & 2,00 & 4 & 0,906 & 32 \\
\hline 32 & Comunicações & 1,46 & 6 & 1,037 & 08 \\
\hline 33 & Instituições Financeiras & 0,94 & 9 & 1,077 & 05 \\
\hline 34 & Serviços Prestados às Famílias e Empresas, Inclusive Aluguel & 5,15 & 1 & 0,994 & 23 \\
\hline 35 & Administração Pública & 0,42 & 34 & 1,015 & 14 \\
\hline
\end{tabular}

Fonte: Elaboração própria. 


\subsection{Multiplicadores de impacto total}

A partir da matriz de insumo-produto pode-se encontrar os multiplicadores de impacto sobre determinadas variáveis macroeconômicas estaduais. Estes resultados derivados consideram as interrelações setoriais observadas na matriz de coeficientes técnicos. Em outras palavras, eles levam em conta o encadeamento direto e indireto de todas as atividades fornecedoras de insumos a uma determinada atividade. Posto desta forma, os multiplicadores medem o impacto de um aumento unitário na demanda final de determinado setor sobre todos os setores que possuem algum grau de conexão (ligação) com este. Feijó et al. (2003) expõem três tipos de multiplicadores:

Multiplicador direto - mede o impacto de variações na demanda final do j-ésimo setor, considerando somente as atividades que fornecem insumos diretos a esse setor;

Multiplicador indireto - mede o impacto de variações na demanda final do j-ésimo setor, considerando somente as atividades que fornecem insumos indiretos a esse setor;

Multiplicador efeito-renda - mede o impacto de variações na demanda final do j-ésimo setor, considerando a variação adicional da demanda provocada pelo incremento no nível de rendimentos da economia quando um setor é estimulado.

Os multiplicadores totais são encontrados somando-se os três multiplicadores relacionados acima. Neste trabalho são calculados os multiplicadores totais que medem o efeito de um choque na demanda final de cada setor sobre o valor adicionado (V), emprego (E) e rendimento (R). Utilizaram-se os resultados do modelo fechado para encontrar os multiplicares, uma vez que somente a partir dele pode ser apreendido o efeito renda. O cálculo destes multiplicadores é conduzido por meio das seguintes equações:

$$
\begin{aligned}
& \mathrm{V}=\mathrm{v} \cdot \mathrm{Z} \\
& \mathrm{E}=\mathrm{e} \cdot \mathrm{Z} \\
& \mathrm{R}=\mathrm{r} \cdot \mathrm{Z}
\end{aligned}
$$

em que v, e e r são os vetores linha dos coeficientes do valor agregado, emprego e rendimento, respectivamente, por unidade de produto de cada atividade.

Os resultados dos multiplicadores podem ser bastante úteis para nortear políticas de desenvolvimento regional, uma vez que eles podem ser entendidos como sendo o impacto de um aumento unitário da demanda final do j-ésimo setor sobre qualquer uma das três variáveis consideradas (valor adicionado, emprego e rendimento) de todos os setores ligados direta e indiretamente com o setor $\mathrm{j}$.

Na MIP-PE, a unidade monetária é expressa em milhões de reais. Portanto, para interpretar, por exemplo, o multiplicador de renda ou valor adicionado em termos monetários utiliza-se o seguinte raciocínio: a magnitude do multiplicador também é expressa em milhões de reais, de forma que o valor do multiplicador indica a renda gerada em virtude de um aumento de $\mathrm{R} \$ 1$ milhão na 
demanda final do j-ésimo setor. No caso do multiplicador de emprego, a interpretação é um pouco diferente. $\mathrm{O}$ que se apreende é o número de empregos gerados por um aumento de $\mathrm{R} \$ 1$ milhão na demanda final da atividade $\mathrm{j}$.

Os multiplicadores de emprego, renda e valor adicionado são apresentados na Tabela 3. Da mesma forma como se procedeu com os indicadores síntese, construiu-se um ranking para que fique claro quais são os setores com maior potencial para gerar empregos, renda e VA.

Com relação ao multiplicador de empregos, a Agropecuária, seguida por Madeira e Mobiliário, Indústria do Açúcar, Fabricação de Artigos do Vestuário e Acessórios, e Transporte representam as cinco atividades que mais empregam na economia pernambucana. A Agropecuária situa-se como uma atividade tradicional empregadora de mão-de-obra no Estado, o mesmo ocorrendo com a Indústria do Açúcar. A atividade Transporte faz parte do setor de serviços, muito forte na economia pernambucana. Já as atividades de Madeira e Mobiliário e Fabricação de Artigos do Vestuário e Acessórios representam duas crescentes atividades na economia pernambucana, principalmente a Fabricação de Artigos do Vestuário e Acessórios. Com relação ao multiplicador de renda, Madeira e Mobiliário, seguida pelo Comércio, Serviços Prestados às Famílias e Empresas, Inclusive Aluguel, Indústrias Diversas, e Indústria de Minerais Não-metálicos representam as cinco atividades que mais geram renda na economia pernambucana. Estes resultados indicam que o setor industrial em Pernambuco ainda está entre aqueles que mais geram renda na economia, seguido pelo setor serviços. Por último, quando se observam os resultados obtidos com relação ao multiplicador de valor adicionado, tem-se que o setor de serviços merece destaque, englobando as cinco primeiras atividades no ranking estimado para o Estado de Pernambuco. Em ordem decrescente, tem-se: Administração Pública; Instituições Financeiras; Comércio; Serviços Prestados às Famílias e Empresas, Inclusive Aluguel; e Comunicações.

Para efeito de comparação, a Figura $1^{12}$ apresenta, em conjunto, os multiplicadores acima calculados de forma normalizada. A leitura desta figura pode ser feita da seguinte forma: o setor Agropecuária possui um multiplicador de emprego normalizado superior a 2. Enquanto isso, os demais multiplicadores normalizados deste setor estão entre 0,8 e 1,2. Seguindo este raciocínio, examinando os multiplicadores do setor Madeira e Mobiliário percebe-se que ele possui um multiplicador de emprego normalizado bastante próximo de 2, enquanto isso, possui um multiplicador de renda normalizado maior do que 2. No elenco de setores apresentados na Figura 1, aqueles que apresentam maiores multiplicadores de emprego, renda, valor adicionado e produção são também aqueles que, conseqüentemente, deverão servir de alvo para políticas expansionistas. Em um ambiente econômico de limitações na disponibilidade de recursos para investimentos em determinados setores, o investimento deve ser voltado para aqueles setores que geram o maior impacto sobre empregos, renda, valor adicionado e produção, juntos. Neste sentido, e de acordo com a Figura 1, os setores Agropecuária, Madeira e Mobiliário, Fabricação de Artigos do Vestuário e Acessórios, Indústria do Açúcar, e Comércio se destacam.

12 Os códigos apresentados na Figura 1 referem-se às atividades descritas nas Tabelas de 2 e 3. 
Tabela 3 - Multiplicadores de impacto sobre emprego, renda e valor adicionado

\begin{tabular}{|c|c|c|c|c|c|c|c|}
\hline Código & Descrição da atividade & Emprego & Rank & Renda & Rank & VA & Rank \\
\hline 01 & Agropecuária & 555 & 1 & 0,671 & 10 & 1,576 & 7 \\
\hline 02 & Indústria Extrativa & 184 & 29 & 0,437 & 29 & 1,388 & 19 \\
\hline 03 & Minerais Não-metálicos & 323 & 9 & 0,808 & 5 & 1,317 & 22 \\
\hline 04 & Siderurgia & 188 & 28 & 0,482 & 25 & 1,520 & 11 \\
\hline 05 & Metalurgia dos Não-ferrosos & 200 & 24 & 0,534 & 17 & 1,555 & 8 \\
\hline 06 & Fabricação de Outros Produtos Metalúrgicos & 192 & 27 & 0,452 & 27 & 1,476 & 12 \\
\hline 07 & Fabricação e Manutenção de Máquinas e Tratores & 217 & 21 & 0,584 & 15 & 1,413 & 15 \\
\hline 08 & Material Elétrico-Eletrônico & 178 & 30 & 0,492 & 24 & 1,324 & 21 \\
\hline 09 & Autoveículos, Peças e Acessórios & 167 & 32 & 0,426 & 32 & 1,163 & 29 \\
\hline 10 & Madeira e Mobiliário & 485 & 2 & 1,329 & 1 & 1,207 & 26 \\
\hline 11 & Indústria de Papel e Gráfica & 215 & 22 & 0,631 & 12 & 1,348 & 20 \\
\hline 12 & Indústria da Borracha & 196 & 26 & 0,427 & 31 & 1,211 & 25 \\
\hline 13 & Indústria Química & 254 & 14 & 0,496 & 23 & 1,396 & 18 \\
\hline 14 & Refino de Petróleo e Indústria Petroquímica & 135 & 34 & 0,297 & 34 & 0,977 & 34 \\
\hline 15 & Fabricação de Produtos Farmacêuticos e de Perfumaria & 174 & 31 & 0,445 & 28 & 1,143 & 30 \\
\hline 16 & Indústria de Transformação de Material Plástico & 164 & 33 & 0,425 & 33 & 1,121 & 31 \\
\hline 17 & Indústria Têxtil & 249 & 16 & 0,516 & 19 & 1,092 & 32 \\
\hline 18 & Fabricação de Artigos do Vestuário e Acessórios & 435 & 4 & 0,799 & 7 & 1,240 & 23 \\
\hline 19 & Fabricação de Calçados e de Artigos de Couro e Pele & 252 & 15 & 0,584 & 16 & 1,223 & 24 \\
\hline 20 & Indústria do Café & 128 & 35 & 0,288 & 35 & 0,726 & 35 \\
\hline 21 & Beneficiamento de Produtos de Origem Vegetal, Inclusive Fumo & 277 & 11 & 0,469 & 26 & 1,206 & 27 \\
\hline 22 & Abate e Preparação de Carnes & 365 & 6 & 0,679 & 9 & 1,409 & 16 \\
\hline 23 & Resfriamento e Preparação do Leite e Laticínios & 227 & 20 & 0,503 & 22 & 1,528 & 10 \\
\hline 24 & Indústria do Açúcar & 436 & 3 & 0,804 & 6 & 1,580 & 6 \\
\hline 25 & Óleos Vegetais e Gorduras para Alimentação & 236 & 17 & 0,435 & 30 & 1,174 & 28 \\
\hline 26 & Outras Indústrias Alimentares e de Bebidas & 273 & 12 & 0,630 & 13 & 1,415 & 14 \\
\hline 27 & Indústrias Diversas & 303 & 10 & 0,846 & 4 & 1,406 & 17 \\
\hline 28 & Serviços Industriais de Utilidade Pública & 198 & 25 & 0,521 & 18 & 1,529 & 9 \\
\hline 29 & Construção Civil & 262 & 13 & 0,512 & 20 & 1,468 & 13 \\
\hline 30 & Comércio & 359 & 7 & 0,942 & 2 & 1,663 & 3 \\
\hline 31 & Transporte & 388 & 5 & 0,626 & 14 & 0,999 & 33 \\
\hline 32 & Comunicações & 208 & 23 & 0,505 & 21 & 1,617 & 5 \\
\hline 33 & Instituições Financeiras & 235 & 19 & 0,714 & 8 & 1,667 & 2 \\
\hline 34 & Serviços Prestados às Famílias e Empresas, Inclusive Aluguel & 344 & 8 & 0,846 & 3 & 1,652 & 4 \\
\hline 35 & Administração Pública & 236 & 18 & 0,649 & 11 & 1,723 & 1 \\
\hline
\end{tabular}

Fonte: Elaboração própria. 
Figura 1 - Multiplicadores de impacto normalizados

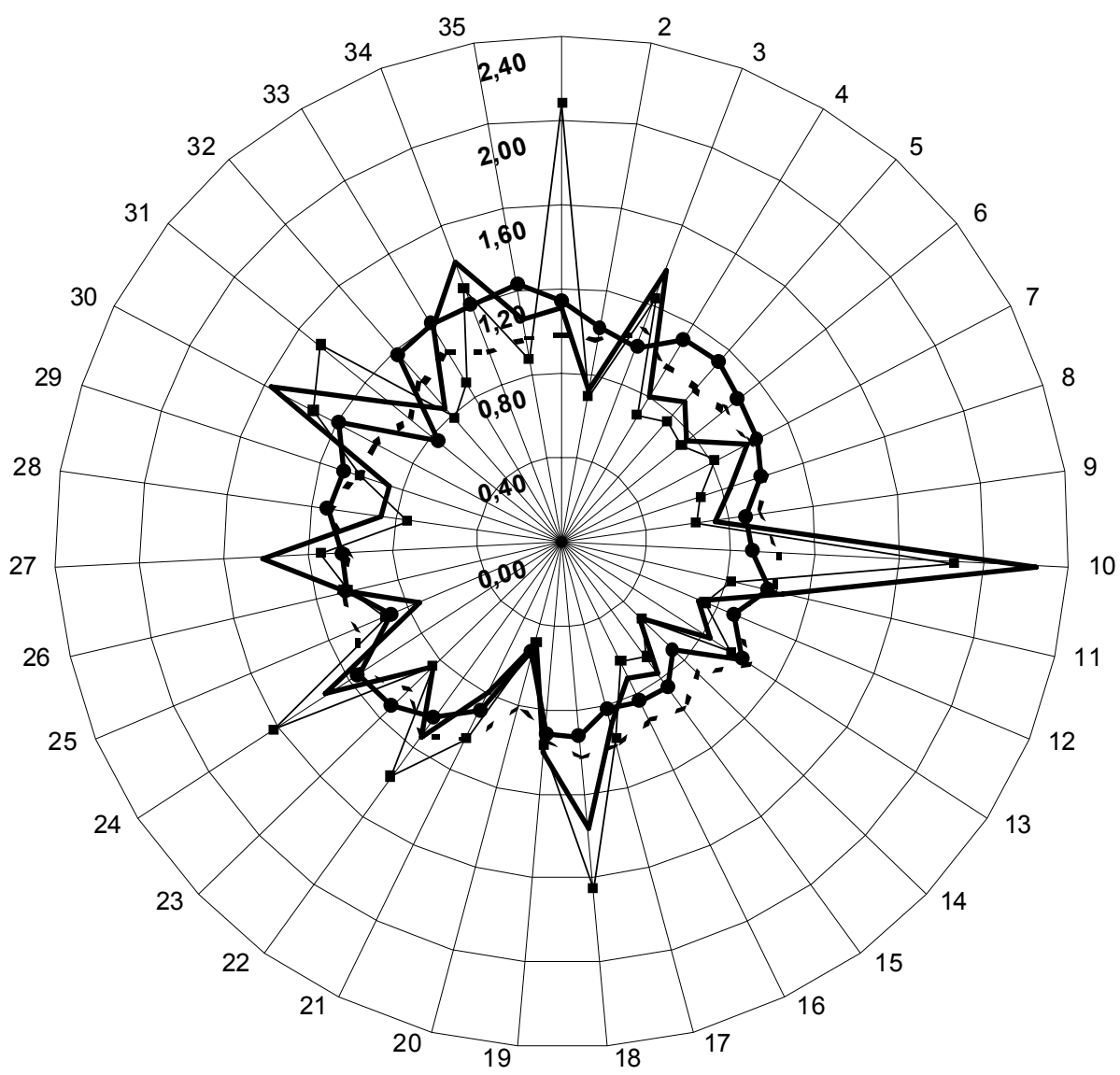

$\longrightarrow$ Valor Adicionado - - - - Produção — Emprego — Renda

Fonte: Elaboração própria.

5.3 Adensamento de cadeias produtivas via internalização das importações interestaduais e internacionais

No Estado de Pernambuco, as importações (internacionais e interestaduais) representam 70,2\% do PIB estadual. Desagregando o consumo intermediário em uma parcela produzida domesticamente e em outra produzida fora do Estado, observa-se que 29,6\% dos bens e serviços utilizados como consumo intermediário são importados. Fazendo a mesma análise nos elementos de demanda final, tem-se que 31,8\% do consumo das famílias são importados, 14,3\% dos bens e serviços utilizados na formação bruta do capital fixo são importados e 13,0\% dos bens que compõem a formação de estoque são importados. Ao examinar as exportações pernambucanas, constata-se que 72,3\% dos produtos exportados são compostos de produtos importados outrora. Estes números in- 
dicam uma forte presença das importações na economia pernambucana, o que faz suscitar algumas indagações no que diz respeito aos potenciais efeitos positivos de um adensamento das cadeias produtivas do Estado. De fato, políticas de adensamento de cadeias produtivas têm feito parte da agenda de ações de vários governos como forma de estimular a atividade econômica local, gerar novos postos de trabalho e, conseqüentemente, gerar renda para a população local (como exemplo, ver Instituto de Pesquisa e Informação do Estado do Ceará - IPLANCE, 2005). Entretanto, sabe-se pouco sobre a magnitude e direção destes possíveis efeitos. A disponibilidade desse conjunto de informações pode ser útil para avaliar a eficácia deste tipo de política e/ou nortear a sua implementação.

Neste sentido, conduziu-se, nesta seção, um exercício de simulação utilizando o modelo de insumo-produto aqui exposto, onde internalizou-se as importações de todos os setores da economia pernambucana com o intuito de observar os efeitos oferecidos por uma política de adensamento total de todas as cadeias produtivas. Em outras palavras, os indicadores síntese e os multiplicadores foram re-calculados considerando que $100 \%$ das importações interestaduais e internacionais passariam a ser produzidas dentro do Estado de Pernambuco, preenchendo todas as lacunas das diversas cadeias produtivas. Apesar de ser uma situação pouco verossímil, os resultados advindos deste exercício indicam possíveis direções dos efeitos dessa política.

Esta simulação só é possível de ser implementada porque foram construídas as tabelas de destino, onde o consumo intermediário das atividades e elementos de demanda final foram desagregados em bens produzidos domesticamente e importados de outros estados e do exterior.

Entretanto, é importante destacar algumas limitações da metodologia utilizada. A primeira delas diz respeito ao fato do estudo levar em conta que todas as atividades econômicas consideradas encontrariam uma situação ideal para produzir no Estado de Pernambuco. Não se faz nenhuma consideração sobre custos de transportes proibitivos, ausência de retornos de escala, falta de mãode-obra especializada etc., que são parâmetros importantes na decisão de instalação de linhas de produção em determinadas atividades. Outro aspecto importante não levado em conta é a ausência de possíveis reações por parte das empresas exportadoras, que perderiam mercado caso seu produto fosse substituído por um similar produzido domesticamente. Além disso, uma das hipóteses do modelo de Leontief é que o conjunto de preços da economia é fixo para qualquer quantidade ofertada ou demandada.

Todavia, estas limitações não invalidam os resultados alcançados, uma vez que a preocupação deste estudo é apenas apresentar uma direção factível para este tipo de mudança no ambiente econômico, levando em conta toda a interdependência setorial da economia pernambucana e outras formas de alocações de recursos particulares ao Estado de Pernambuco. Um estudo mais rigoroso, no qual poderia ser especificado algum tipo de não-convexidade na estrutura produtiva de determinadas indústrias locais ou dos países e estados de onde se originam as importações, ou estruturas de mercado mais próximas da realidade, poderia ser conduzido com um modelo de equilíbrio geral computável, por exemplo.

Nas Tabelas 4 e 5 estão reportados os índices de ligação para frente e para trás normalizados e os multiplicadores de impacto sobre emprego, renda e valor adicionado calculados após a inclusão das importações interestaduais e internacionais na produção interna do Estado de Pernambuco. Observa-se que os índices de ligação para frente e para trás aumentam substancialmente e que os multiplicadores também sofrem deste acréscimo, devido a uma maior disponibilidade de indústrias e setores na economia pernambucana. A composição dos setores no ranking também é diretamente alterada, mostrando que alguns setores assumem importância ainda maior quando as importações do Estado são incorporadas na economia, por meio do adensamento total das cadeias produtivas. 
Estes resultados servem de instrumento para que autoridades governamentais possam interferir nos setores que podem passar a gerar mais empregos após um maior adensamento da cadeia produtiva do respectivo setor no Estado.

Tabela 4 - Índices de ligação para frente e para trás

\begin{tabular}{|c|c|c|c|c|c|}
\hline Código & Descrição da atividade & $I_{\mathrm{FN}}$ & Rank & $I_{B N}$ & Rank \\
\hline 01 & Agropecuária & 3,65 & 2 & 0,97 & 31 \\
\hline 02 & Indústria Extrativa & 0,72 & 13 & 0,98 & 24 \\
\hline 03 & Minerais Não-metálicos & 0,33 & 30 & 1,01 & 15 \\
\hline 04 & Siderurgia & 0,40 & 26 & 0,97 & 29 \\
\hline 05 & Metalurgia dos Não-ferrosos & 0,40 & 27 & 0,97 & 33 \\
\hline 06 & Fabricação de Outros Produtos Metalúrgicos & 0,68 & 14 & 0,98 & 23 \\
\hline 07 & Fabricação e Manutenção de Máquinas e Tratores & 0,48 & 21 & 0,98 & 26 \\
\hline 08 & Material Elétrico-eletrônico & 0,63 & 17 & 0,99 & 21 \\
\hline 09 & Autoveículos, Peças e Acessórios & 1,26 & 10 & 1,00 & 18 \\
\hline 10 & Madeira e Mobiliário & 0,30 & 32 & 1,02 & 14 \\
\hline 11 & Indústria de Papel e Gráfica & 0,54 & 19 & 1,00 & 17 \\
\hline 12 & Indústria da Borracha & 0,26 & 33 & 1,00 & 19 \\
\hline 13 & Indústria Química & 1,96 & 6 & 1,02 & 13 \\
\hline 14 & Refino de Petróleo e Indústria Petroquímica & 2,06 & 4 & 1,03 & 4 \\
\hline 15 & Fabricação de Produtos Farmacêuticos e de Perfumaria & 0,73 & 12 & 1,02 & 10 \\
\hline 16 & Indústria de Transformação de Material Plástico & 0,47 & 22 & 1,02 & 9 \\
\hline 17 & Indústria Têxtil & 0,84 & 11 & 1,03 & 6 \\
\hline 18 & Fabricação de Artigos do Vestuário e Acessórios & 0,43 & 23 & 1,01 & 16 \\
\hline 19 & Fabricação de Calçados e de Artigos de Couro e Pele & 0,31 & 31 & 0,99 & 20 \\
\hline 20 & Indústria do Café & 0,22 & 34 & 1,02 & 7 \\
\hline 21 & Beneficiamento de Produtos de Origem Vegetal, Inclusive Fumo & 0,57 & 18 & 1,04 & 1 \\
\hline 22 & Abate e Preparação de Carnes & 0,41 & 25 & 1,04 & 2 \\
\hline 23 & Resfriamento e Preparação do Leite e Laticínios & 0,40 & 28 & 0,98 & 27 \\
\hline 24 & Indústria do Açúcar & 0,50 & 20 & 1,02 & 12 \\
\hline 25 & Óleos Vegetais e Gorduras para Alimentação & 0,66 & 15 & 1,04 & 3 \\
\hline 26 & Outras Indústrias Alimentares e de Bebidas & 1,99 & 5 & 1,02 & 11 \\
\hline 27 & Indústrias Diversas & 0,41 & 24 & 0,99 & 22 \\
\hline 28 & Serviços Industriais de Utilidade Pública & 1,34 & 9 & 1,02 & 8 \\
\hline 29 & Construção Civil & 0,33 & 29 & 0,98 & 25 \\
\hline 30 & Comércio & 2,65 & 3 & 0,97 & 32 \\
\hline 31 & Transporte & 1,82 & 7 & 1,03 & 5 \\
\hline 32 & Comunicações & 1,35 & 8 & 0,97 & 30 \\
\hline 33 & Instituições Financeiras & 0,65 & 16 & 0,98 & 28 \\
\hline 34 & Serviços Prestados às Famílias e Empresas, Inclusive Aluguel & 5,13 & 1 & 0,95 & 35 \\
\hline 35 & Administração Pública & 0,12 & 35 & 0,95 & 34 \\
\hline
\end{tabular}

Fonte: Elaboração própria. 
Tabela 5 - Multiplicadores de impacto sobre emprego, renda e valor adicionado

\begin{tabular}{|c|c|c|c|c|c|c|c|}
\hline Código & Descrição da atividade & Emprego & Rank & Renda & Rank & VA & Rank \\
\hline 01 & Agropecuária & 1186 & 1 & 2,014 & 12 & 4,875 & 4 \\
\hline 02 & Indústria Extrativa & 820 & 30 & 1,810 & 34 & 4,779 & 18 \\
\hline 03 & Minerais Não-metálicos & 967 & 10 & 2,204 & 5 & 4,733 & 23 \\
\hline 04 & Siderurgia & 814 & 32 & 1,835 & 31 & 4,854 & 9 \\
\hline 05 & Metalurgia dos Não-ferrosos & 822 & 28 & 1,875 & 21 & 4,850 & 11 \\
\hline 06 & Fabricação de Outros Produtos Metalúrgicos & 821 & 29 & 1,812 & 33 & 4,842 & 12 \\
\hline 07 & Fabricação e Manutenção de Máquinas e Tratores & 844 & 24 & 1,942 & 18 & 4,772 & 20 \\
\hline 08 & Material Elétrico-Eletrônico & 810 & 34 & 1,869 & 26 & 4,723 & 24 \\
\hline 09 & Autoveículos, Peças e Acessórios & 814 & 33 & 1,839 & 30 & 4,671 & 31 \\
\hline 10 & Madeira e Mobiliário & 1174 & 2 & 2,808 & 1 & 4,690 & 26 \\
\hline 11 & Indústria de Papel e Gráfica & 859 & 21 & 2,029 & 11 & 4,754 & 21 \\
\hline 12 & Indústria da Borracha & 861 & 19 & 1,846 & 28 & 4,734 & 22 \\
\hline 13 & Indústria Química & 900 & 17 & 1,876 & 20 & 4,807 & 15 \\
\hline 14 & Refino de Petróleo e Indústria Petroquímica & 810 & 35 & 1,758 & 35 & 4,677 & 28 \\
\hline 15 & Fabricação de Produtos Farmacêuticos e de Perfumaria & 842 & 25 & 1,871 & 23 & 4,673 & 30 \\
\hline 16 & Indústria de Transformação de Material Plástico & 820 & 31 & 1,842 & 29 & 4,676 & 29 \\
\hline 17 & Indústria Têxtil & 940 & 12 & 1,968 & 15 & 4,634 & 33 \\
\hline 18 & Fabricação de Artigos do Vestuário e Acessórios & 1098 & 3 & 2,208 & 4 & 4,658 & 32 \\
\hline 19 & Fabricação de Calçados e de Artigos de Couro e Pele & 917 & 16 & 2,007 & 14 & 4,689 & 27 \\
\hline 20 & Indústria do Café & 990 & 8 & 1,885 & 19 & 4,613 & 35 \\
\hline 21 & Beneficiamento de Produtos de Origem Vegetal, Inclusive Fumo & 1016 & 7 & 1,943 & 17 & 4,812 & 14 \\
\hline 22 & Abate e Preparação de Carnes & 1027 & 6 & 2,077 & 8 & 4,812 & 13 \\
\hline 23 & Resfriamento e Preparação do Leite e Laticínios & 861 & 20 & 1,852 & 27 & 4,850 & 10 \\
\hline 24 & Indústria do Açúcar & 1064 & 4 & 2,144 & 7 & 4,867 & 6 \\
\hline 25 & Óleos Vegetais e Gorduras para Alimentação & 932 & 14 & 1,869 & 24 & 4,707 & 25 \\
\hline 26 & Outras Indústrias Alimentares e de Bebidas & 931 & 15 & 2,009 & 13 & 4,797 & 16 \\
\hline 27 & Indústrias Diversas & 939 & 13 & 2,221 & 3 & 4,776 & 19 \\
\hline 28 & Serviços Industriais de Utilidade Pública & 823 & 26 & 1,875 & 22 & 4,856 & 8 \\
\hline 29 & Construção Civil & 890 & 18 & 1,869 & 25 & 4,788 & 17 \\
\hline 30 & Comércio & 974 & 9 & 2,263 & 2 & 4,909 & 2 \\
\hline 31 & Transporte & 1059 & 5 & 2,075 & 9 & 4,632 & 34 \\
\hline 32 & Comunicações & 823 & 27 & 1,831 & 32 & 4,866 & 7 \\
\hline 33 & Instituições Financeiras & 849 & 22 & 2,037 & 10 & 4,889 & 3 \\
\hline 34 & Serviços Prestados às Famílias e Empresas, Inclusive Aluguel & 958 & 11 & 2,162 & 6 & 4,870 & 5 \\
\hline 35 & Administração Pública & 846 & 23 & 1,960 & 16 & 4,926 & 1 \\
\hline
\end{tabular}

Fonte: Elaboração própria. 


\section{CONCLUSÕES E DISCUSSÃO}

O procedimento para obtenção da MIP-PE levou em consideração a disponibilidade de dados em nível estadual e a metodologia desenvolvida por outros autores para o tratamento considerado para determinadas variáveis. Conforme já apresentado ao longo do texto, os maiores entraves situaram-se no detalhamento das informações fornecidas pela Secretaria da Fazenda do Estado de Pernambuco e das informações obtidas em nível de quatro dígitos do CNAE da PIA-IBGE.

Todavia, os resultados encontrados refletem a economia pernambucana em termos do agregado macroeconômico e via relações intersetoriais do modelo de insumo-produto. Os encadeamentos das atividades ficaram melhor delineados, possibilitando uma melhor percepção da importância relativa das atividades econômicas no Estado de Pernambuco. A determinação dos multiplicadores de emprego, renda e valor adicionado bem como dos indicadores de síntese podem servir de instrumento para a atuação do governo em nível Estadual e dos Sindicatos e Federações para melhor utilizarem os recursos escassos.

Com relação às relações intersetoriais, foram identificados sete setores-chave em termos de encadeamento para frente (Agropecuária; Indústria Química; Serviços Industriais de Utilidade Pública; Comércio; Transporte; Comunicações; e Serviços Prestados às Famílias e Empresas, Inclusive Aluguel) e quinze setores-chave no encadeamento para trás (Minerais Não-metálicos; Material Elétrico-eletrônico; Madeira e Mobiliário; Indústria de Papel e Gráfica; Indústria Química; Fabricação de Artigos do Vestuário e Acessórios; Beneficiamento de Produtos de Origem Vegetal, Inclusive Fumo; Abate e Preparação de Carnes; Indústria do Açúcar; Óleos Vegetais e Gorduras para Alimentação; Outras Indústrias Alimentares e de Bebidas; Serviços Industriais de Utilidade Pública; Construção Civil; Comunicações; e Instituições Financeiras). Em termos de impactos sobre o emprego, rendimento e VA, os setores que mais se destacam são também de importância e tradição na economia pernambucana, como a Indústria do Açúcar, o Comércio, e a Agropecuária.

Os resultados e as informações obtidas neste estudo permitem disponibilizar, para os pesquisadores, autoridades políticas e econômicas e também para os demais interessados, um conjunto de informações que contribuem para se avançar em estudos específicos associados aos modelos de insumo-produto, notadamente aqueles direcionados ao planejamento do desenvolvimento regional.

Dentre as limitações deste modelo, caberia destacar a orientação, apenas pela ótica da demanda, dos impactos dos resultados. Tal limitação poderia ser contornada por meio da utilização de um modelo de equilíbrio geral computável: uma extensão natural do modelo exposto neste artigo. Nele poderiam ser consideradas as interações entre a oferta e demanda da economia pernambucana, além do comportamento otimizador dos consumidores e dos produtores. É importante ressaltar que os resultados encontrados neste artigo, dentro do processo de construção da matriz de Leontief, são essenciais para a obtenção da Matriz de Contabilidade Social do Estado de Pernambuco, a partir da qual será possível efetuar a implementação de um modelo de equilíbrio geral para o estado, viabilizando a simulação de um espectro mais amplo de políticas de desenvolvimento regional.

\section{REFERÊNCIAS}

Bacharach, M. Biproportional matrices and input-output change. London: Cambridge University Press, 1970.

Banco Central do Brasil. Taxa de câmbio média, 1999. 2003. Disponível em: < http://www.bcb.gov.br>. Acessado em dezembro de 2003. 
Feijó, C. A.; Ramos, R. L. O.; Young, C. E. F.; Lima, F. C. G. C.; Galvão, O. J. A. Contabilidade social: o novo sistema de contas nacionais do Brasil. 2a ed. Rio de Janeiro: Campus, 2003.

Fundação Getúlio Vargas - FGV. Índice geral de preços. Disponível em: < http://fgudados.fgv.br/>. Acessado em: dezembro de 2003.

Guilhoto, J. J. M.; Sesso Filho, U. A.; Lopes, R. L.; Hilgemberg, C. M. A. T.; Hilgemberg, E. M. Nota metodológica: construção da matriz insumo-produto utilizando dados preliminares das contas nacionais. Anais do II Encontro de Estudos Regionais e Urbanos. São Paulo, 25 a 26 de outubro, 2002, CD-ROM.

Haguenauer L.; Bahia, L. D.; Castro, P. F.; Ribeiro, M. B. Evolução das cadeias produtivas brasileiras na década de 90. Ipea, Texto para Discussão 786, 2001.

Instituto Brasileiro de Geografia e Estatística - IBGE. Matriz de insumo-produto do Brasil. Rio de Janeiro: IBGE. (Série Relatórios Metodológicos, v. 18). 21p., 1997a.

--. Sistema de contas nacionais: tabelas de recursos e usos: metodologia. Rio de Janeiro: IBGE. (Textos para Discussão, n. 88). 49p., 1997 b.

------. Censo Agropecuário 1995/1996: Pernambuco. Volume 12. Rio de Janeiro: IBGE, 1998.

--.---. Pesquisa de orçamentos familiares 1995-1996: despesas, recebimentos e características das famílias, domicílios, pessoas e locais de compra. Volume 1. Rio de Janeiro: IBGE, 1999a.

-.----. Pesquisa de orçamentos familiares 1995-1996: consumo alimentar domiciliar per capita. Volume 2. Rio de Janeiro: IBGE, 1999b.

-.---.-. Pesquisa nacional por amostra de domicílios 1999: síntese de indicadores. Rio de Janeiro: IBGE, 2000.

-.---.- Pesquisa anual de serviços 1998-1999. Volume 1. Rio de Janeiro: IBGE, 2001a.

-----.. Pesquisa anual de comércio 1999. Volume 11. Rio de Janeiro: IBGE, 2001b.

. Pesquisa industrial anual 1999: empresa. Volume 18. Rio de Janeiro: IBGE, 2001c.

. Contas regionais do Estado de Pernambuco. Rio de Janeiro: IBGE, 2002a.

Sistema de contas nacionais Brasil 1999-2001. Rio de Janeiro: IBGE. (Textos para Discussão, n. 88). 49p., 2002b.

Regionalização das transações do setor público 1999. Rio de Janeiro: IBGE, 2002c.

-..-.--. Produção agrícola municipal 1999. 2003. Disponível em: < http://www.ibge.gov.br>. Acessado em: dezembro de 2003.

Instituto de Pesquisa e Informação do Estado do Ceará - IPLANCE. Diagnóstico das cadeias produtivas do Estado do Ceará. 2005. Disponível em: < http://www.iplance.ce.gov.br/estudos_setoriais/CadeiaProdutiva/Diagnostico_CP.htm>. Acessado em: abril de 2005.

Miller, E. R.; Blair, D. P. Input-otput analysis: foundations and extensions. New Jersey: Prentice Hall, 1985.

Ministério de Desenvolvimento, Indústria e Comércio Exterior. - MDIC. Secretaria de Comércio Exterior - SECEX, Departamento de Planejamento e Comércio Exterior, 2003. Disponível em: < http:// www.desenvolvimento.gov.br/sitio/secex/>. Acessado em: novembro 2003.

Nunes, E. P. Sistema de contas nacionais: a gênese das contas nacionais modernas e a evolução das contas nacionais no Brasil. 1998. Tese (Doutorado), UNICAMP, Campinas -SP.

Organizações das Nações Unidas - ONU. Handbook of input-output table compilation and analysis. Manuscript for editing and publication, New York: Statistics Division, 1999.

Porsse, A. A. Matriz de insumo-produto estadual: metodologia e resultados para o Rio Grande do Sul. Anais do VII Encontro da ANPEC. Fortaleza, CE, 2002. 


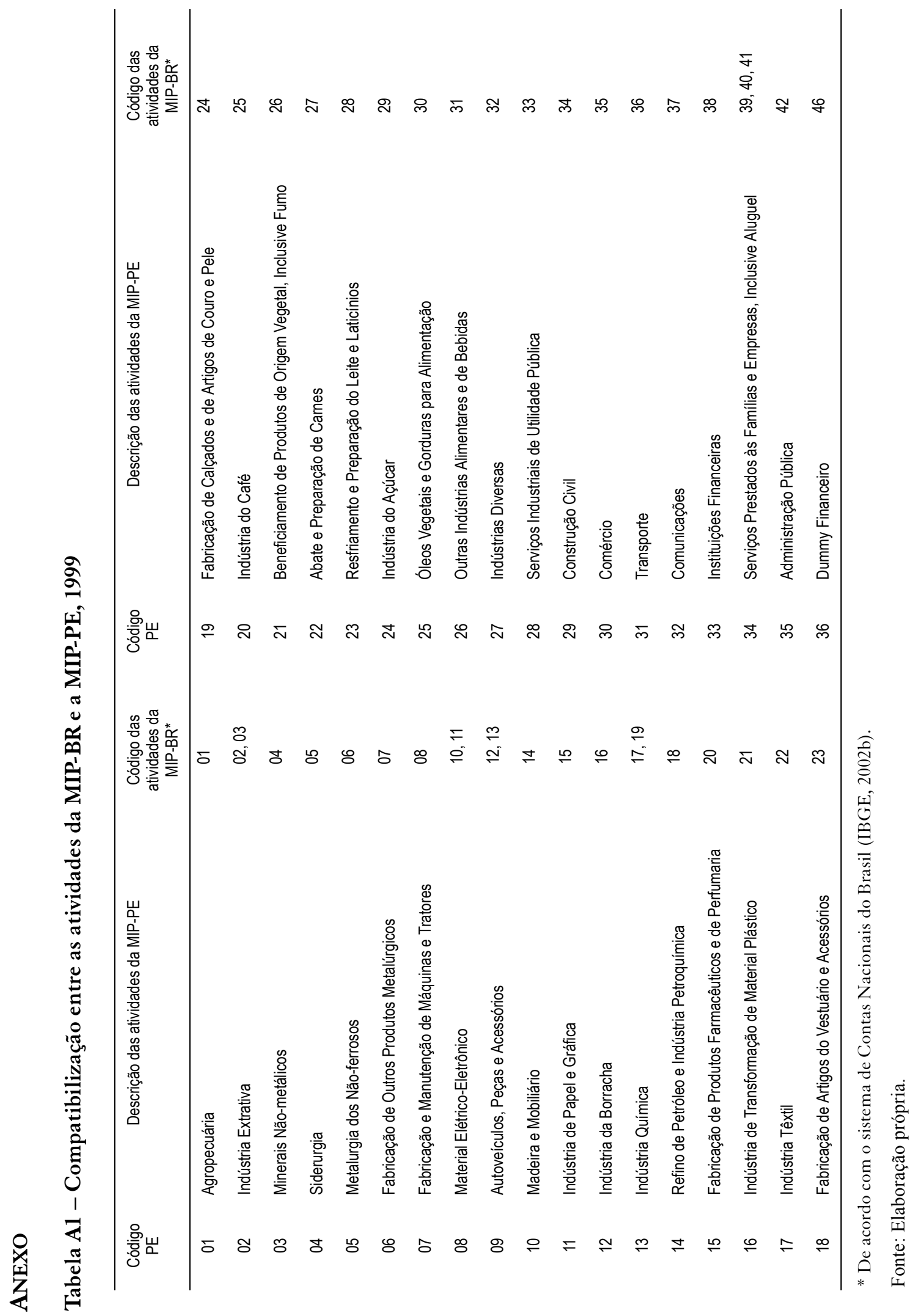




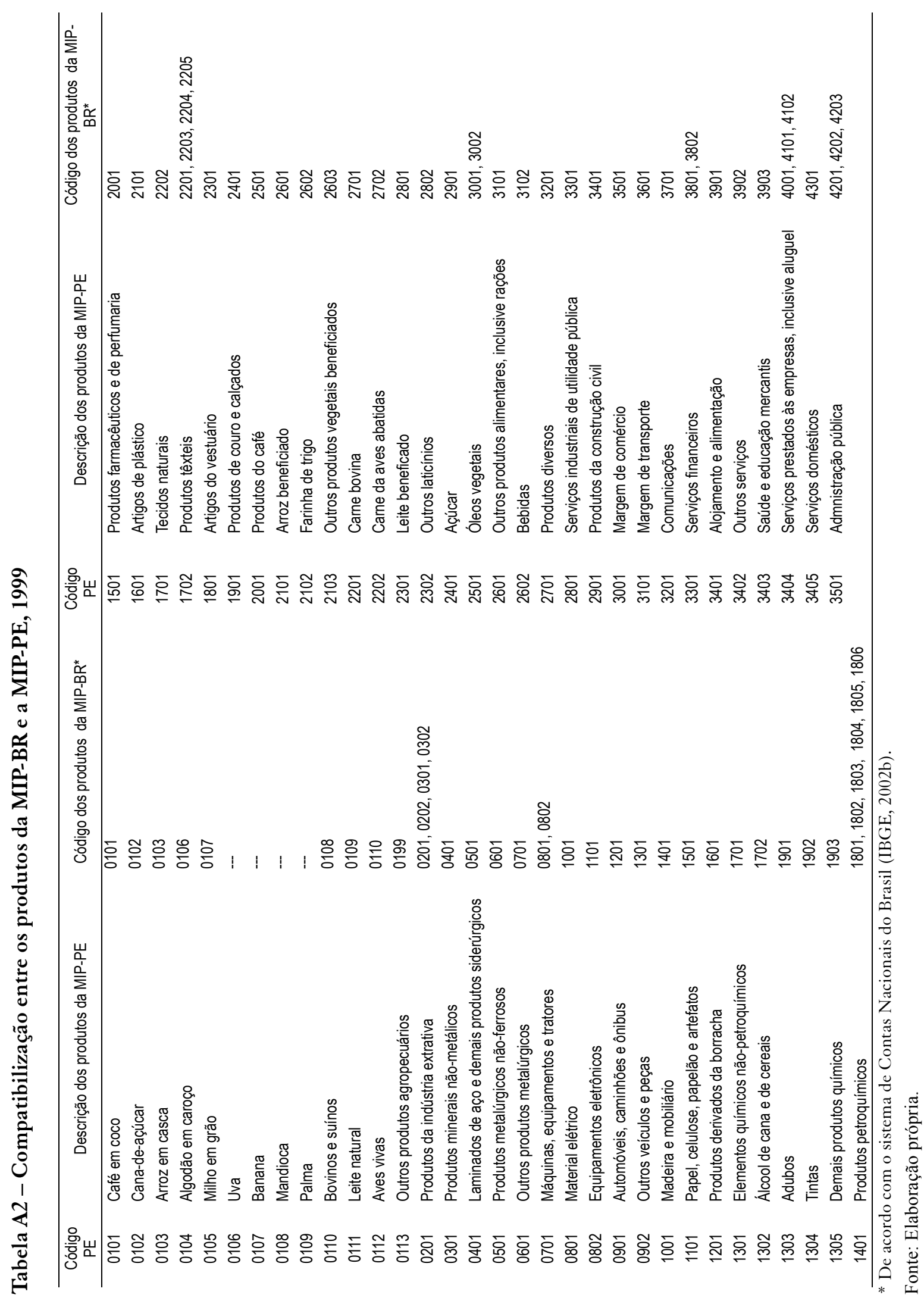


Tabela A3 - Fontes dos dados primários utilizados na construção das estatísticas da MIP-PE, 1999

\begin{tabular}{ll}
\hline Descrição da estatística & \multicolumn{1}{c}{ Fonte dos dados } \\
\hline Valor de produção das atividades a preços básicos & $\begin{array}{l}\text { IBGE: Contas Regionais, Censo Agropecuário de 1996, } \\
\text { PAM, PIA, PAS e PNAD; FGV. }\end{array}$ \\
Consumo intermediário das atividades a preços básicos & $\begin{array}{l}\text { IBGE: Contas Regionais, Censo Agropecuário de 1996, } \\
\text { PAM, PIA, PAS e PNAD; FGV. }\end{array}$ \\
Exportações e importações internacionais & $\begin{array}{l}\text { SECEX, Ministério do Desenvolvimento, Indústria e } \\
\text { Comércio Exterior; BACEN. }\end{array}$ \\
Exportações e importações interestaduais & Secretaria da Fazenda de Pernambuco. \\
Impostos indiretos sobre a produção e importação & IBGE: Regionalização das Transações do Setor Público \\
(RTSP) e TRU; Secretaria da Fazenda de PE. & IBGE: RTSP. \\
Matros impostos ligados a produção & IBGE: Tabela de Recursos do Brasil. \\
Consumo do governo & IBGE: Contas Regionais. \\
Consumo das famílias & IBGE: POF e PNAD. \\
Formação bruta de capital fixo & IBGE: TRU, Censo Agropecuárias e Contas Regionais. \\
Variação de estoques & IBGE: TRU, Censo Agropecuário e Contas Regionais. \\
Remuneração dos empregados, inclusive autônomos & IBGE: PNAD, RTSP e Contas Econômicas Integradas \\
(CEI). & IBGE: PNAD. \\
\hline Pessoal ocupado &
\end{tabular}

Fonte: Elaboração própria. 


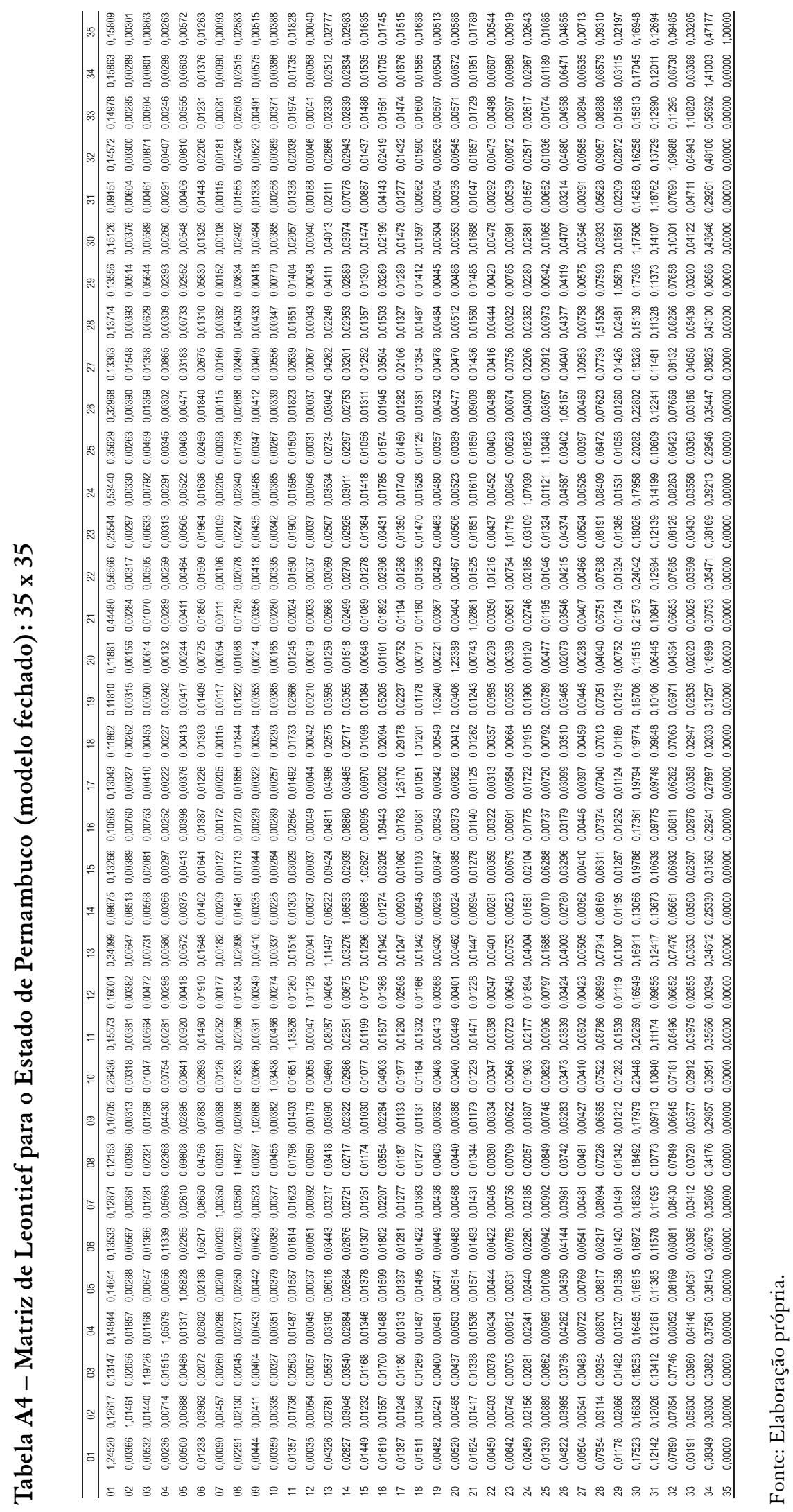

